\title{
Análise qualitativa de preparações de cardápios de uma unidade de alimentação e nutrição em Brasília*
}

\section{Qualitative analysis of menus preparations from a food and nutrition unit in Brasília}

Ana Luiza Pereira Barrozo' Karina Aragão Nobre Mendonça²
Recebido em: 14/04/2015. Aprovado em: 01/10/2015.

Aluna do curso de nutrição do Centro Universitário de Brasília - UniCEUB, Brasil, Brasília

2 Nutricionista formada pela Universidade de Brasília - UnB, com mestrado em Nutrição Humana pela UnB. Coordenadora e professora do curso de nutrição do Centro Universitário de Brasília - UniCEUB, Brasil, Brasília.

\section{Resumo}

A alimentação fora de casa favorece escolhas alimentares não saudáveis e pode trazer malefícios à saúde coletiva. As Unidades de Alimentação e Nutrição (UAN) tendem a trazer qualidade nutricional adequada além de níveis de sanidade. O objetivo do trabalho consistiu em avaliar qualitativamente as preparações de cardápios de uma UAN de Brasília utilizando o método de Avaliação Qualitativa das Preparações do Cardápio adaptado. Em relação aos resultados, compreendeu-se que, a respeito das técnicas de cocção, a maioria das preparações dos cardápios são feitas em calor úmido. Houve presença de frituras (5,58\%). Verificouse ainda maior utilização de carnes gordurosas devido a melhor aceitação do público. As frutas e hortaliças são oferecidas todos os dias. Com relação à cor e à textura das refeições, são bem harmoniosas, coloridas e sem monotonia. Foi possível concluir que a presença do nutricionista na montagem dos cardápios é essencial para se oferecer alimentação saudável e balanceada.

Palavras-chave: Cardápio. Análise qualitativa. Combinação. Preparações.

\begin{abstract}
Eating out favors unhealthy food choices and can bring harm to public health. The Food and Nutrition Unit tend to bring suitable nutritional quality menu as well as health levels. The objective of this work was to qualitatively evaluate menus preparations in a Food and Nutrition Unit in Brasília using an adapted qualitative evaluation of menu preparations (AQPC) method. The work had as results, in relation of cooking techniques, is that most menus preparations were made with humid heat. There was the presence of fried food (5.58\%). Was verified the largest prevalence of fat meat because of better public's acceptance. The fruits and vegetables were offered everyday there. Regarding the color and texture of the meals they are well harmonious, colorful and without monotony. It was concluded that the presence of a nutritionist in the assembly of the menus is essential to provide healthy and balanced diet.
\end{abstract} Keywords: Menu. Qualitative analysis. Combination. Preparations. 


\section{Introdução}

A intensa urbanização e industrialização, ocorridas durante a década de 50 e 60, são decorrentes de diferentes aspectos, como: mudanças tecnológicas, novas estratégias de marketing dos alimentos, variações na renda das famílias, conhecimento das pessoas sobre alimentação, o crescimento da mulher no mercado de trabalho, elevação do nível de vida e educação. Estes são determinantes centrais da modificação do padrão alimentar (CLARO et al., 2009).

Hoje, como os alimentos estão disponíveis em maior volume, a praticidade de se obter os alimentos vem crescendo, surgindo novo desafio ou ainda dificuldades, representadas pela escolha dos alimentos, gerenciamento de sua diversidade e das informações sobre se é saudável, se deve ou não ser consumido, a quantidade adequada, frequência, entre outros aspectos (LEAL, 2010).

Em 2009, a Pesquisa de Orçamentos Familiares (POF) (INSTITUTO BRASILEIRO DE GEOGRAFIA E ESTATÍSTICA, 2010) afirmou que a população brasileira urbana direciona cerca de $33,0 \%$ da renda total com a alimentação fora do lar, o que é o motivo de preocupação devido às escolhas alimentares pouco saudáveis. E, com esses dados, é possível analisar que o número de refeições fora de casa tem aumentado devido à disponibilidade de tempo sugeridos à alimentação.

Com a alimentação fora de casa aumentando com frequência e as escolhas alimentares pouco saudáveis, o crescimento da obesidade constitui problema significante de saúde pública no país e pode trazer como consequências diversas dificuldades psicossociais, sejam elas a discriminação, socialização diminuída e autoimagem negativa, além de riscos para desencadear Doenças Crônicas Não Transmissíveis (DCNT) como, por exemplo, hiperlipidemia, hipertensão e diabetes mellitus (MAHAN; STUMP, 2003).

Dessa forma, as Unidades de Alimentação e Nutrição (UAN) são um espaço para desempenho das atividades relacionadas à alimentação e nutrição, obtendo por principal objetivo fornecer refeições equilibradas nutricionalmente e apresentar bom nível de sanidade e qualidade no preparo dos alimentos. Quando há planejamento do cardápio adequado por nutricionista, há prevalência maior da qualidade da saúde do cliente (VEIROS, 2003). Além disso, uma alimentação adequada implica garantia
Programa de Alimentação do trabalhador (PAT), de forma a aumentar a produtividade e reduzir riscos de trabalho (BRASIL, 2006).

Para o planejamento de cardápios, é necessário observar a quantidade e fluxo de clientes, avaliando os hábitos alimentares e necessidades nutricionais, além de verificar safra, a oferta, o custo dos gêneros alimentícios do mercado, da mão de obra, da disponibilidade do espaço físico, do preparo e do consumo efetivo dos alimentos para garantir que o cardápio possa vir a gerar lucro e qualidade de vida (PASSOS, 2008).

Para garantir que o cardápio planejado tenha o mesmo padrão de qualidade, o instrumento adequado para auxílio do nutricionista são as Fichas Técnicas de Preparação (FTP). A ficha deve conter os ingredientes, quantidade, rendimento, fator de correção, fator de cocção, modo de preparo e composição centesimal de macro e micronutrientes da preparação (VEIROS, 2003).

O método de Avaliação Qualitativa das preparações do Cardápio (AQPC), criado e desenvolvido por Veiros e Proença (2003), visa auxiliar o nutricionista na elaboração de cardápio adequado tanto para aspectos sensoriais quanto nutricionais. Esse método tem como critérios avaliar a composição do cardápio: as cores, técnicas de preparo, repetições, combinações e oferta de frutas, folhosos ou tipo de carnes.

Visto a importância do planejamento de cardápio de uma UAN para a oferta de uma alimentação equilibrada nutricionalmente tendo como foco a promoção da saúde da clientela, este trabalho tem como objetivo avaliar qualitativamente o cardápio de uma UAN.

\section{Metodologia}

Tratou-se de um estudo transversal e observacional, em que foram analisados qualitativamente os cardápios de uma UAN localizada em Brasília-DF durante o mês de setembro de 2014.

A UAN estudada é uma unidade de médio porte que fornece almoço, cerca de 300 refeições diárias, e é aberto ao público. É um restaurante de autosserviço, ou comumente dito self-service, e é supervisionado por um nutricionista.

O cardápio oferecido na UAN é composto por sete opções de salada que contêm alface, um tipo de folhagem, tomate, dois tipos de vegetais cozidos, um vegetal cru e uma salada elaborada ou mista. Há três opções diárias de 
pratos principais variando entre carne branca, carne vermelha, peixe e ovos, quatro guarnições e três acompanhamentos, sendo duas opções de arroz e um tipo de feijão. Há também cinco variedades de frutas para sobremesa e dois tipos de sucos.

Para a análise, foi realizado o método de Avaliação Qualitativa das preparações criado e desenvolvido por Veiros e Proença (2003), adaptado por Costa (2012) cuja finalidade consiste em realizar avaliação global e qualitativa das preparações elaboradas para atender determinado público. Esse método está relacionado aos seguintes critérios:

1) técnicas de cocção empregadas nas preparações:

a) calor úmido: água em ebulição, cocção a vapor propriamente dito, cocção a vapor sob pressão;

$\beta)$ calor seco: grelhado, assado, imersão em fritura, micro-ondas;

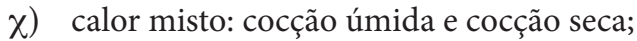

ঠ) presença de frituras.

Além disso, também foi incluído na avaliação:

2) presença de carnes com alto teor de gordura (bovina, suína);

3) cor das preparações e dos alimentos empregados nas refeições;

4) presença de frutas e hortaliças;

5) textura dos alimentos combinados (seco ou úmido);

6) grupo alimentar mais oferecido ao público (carboidratos, proteínas e lipídeos).

Foram adotadas as carnes bovinas ou suínas como gordurosas, pois, calculando a média aritmética dos valores de lipídeos fornecidos para todas as preparações dessas duas opções na Tabela de Composição dos Alimentos (LIMA, 2006), o valor encontrado foi de 14,3g a cada $100 \mathrm{~g}$ da carne, enquanto para as preparações com carne de aves ou peixe, seguindo o mesmo critério, o valor encontrado foi de 9,93g de lipídeos (COSTA, 2012).

Os cardápios eram criados semanalmente e as análises foram feitas com base nas preparações dos dias. As análises foram feitas separando-as pelo número de preparações com ou sem técnicas de cocção. Após calculados os dias da semana, foram geradas as médias semanais e todas as semanas analisadas obtiveram média mensal criada a fim de facilitar a descrição, leitura e comparação dos dados.
Os dados foram tabulados e apresentados em forma de gráficos no Excel (2010).

\section{Resultados}

\subsection{Técnicas de cocção}

A Figura 1 aponta as técnicas de cocção empregadas na UAN estudada. É possível verificar, com base em médias das preparações feitas mensalmente, que a prevalência de preparações utilizando o calor úmido foi de $67,9 \%(\mathrm{~N}=164), 26,1 \%(\mathrm{~N}=51)$ de calor seco, sendo 5,6\% $(\mathrm{N}=16)$ de frituras, e $6,1 \%(\mathrm{~N}=21)$ de misto.

Figura 1 - Percentual das preparações em relação ao tipo de cocção utilizada

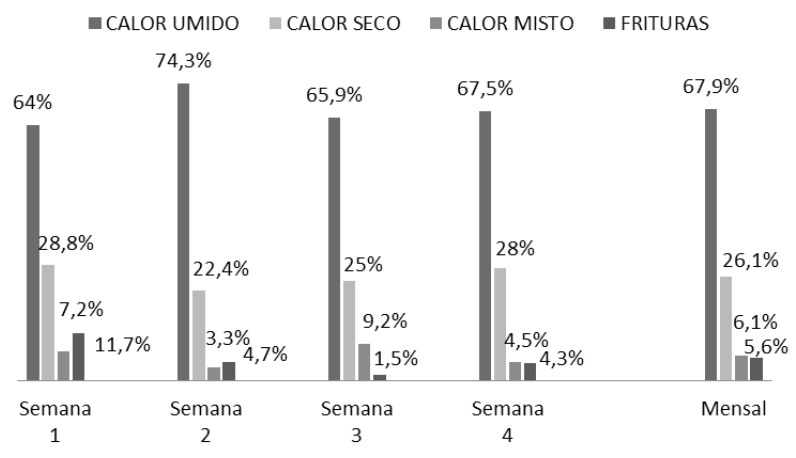

\subsection{Presença de carnes gordurosas}

Na Figura 2, é possível analisar a presença de carnes com alto teor de gorduras $(53,1 \%)$ e com menor teor de gordura $(39,4 \%)$. Todas as semanas avaliadas apresentaram a oferta de ovos no cardápio, com uma média mensal de $7,6 \%$.

Figura 2 - Percentual de presença de carnes nas preparações.

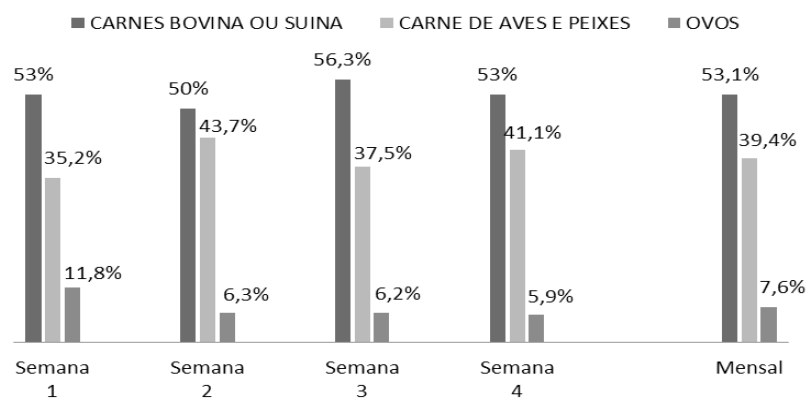

\subsection{Presença de frutas e hortaliças}

Foi possível observar que há presença em 100\% do cardápio de frutas e hortaliças sendo oferecidas diariamente. E os sucos ofertados são de polpa, exceto limão, laranja e maracujá que são preparados da própria fruta. 


\subsection{Cores das refeições}

Com relação à combinação de cores das preparações, notou-se $100 \%$ de adequação no cardápio, com ofertas de preparações bem coloridas. As preparações são bem harmoniosas e variadas não deixando com que o cardápio seja visualmente monótono.

\subsection{Textura}

Em relação à adequação da combinação de textura nas refeições, o cardápio está 100\% adequado, nota-se a presença de combinações de alimentos com texturas diferenciadas.

\subsection{Grupos alimentares presentes}

Os grupos alimentares mais oferecidos foram calculados de acordo com a divisão de macronutrientes (carboidratos, proteínas e lipídeos) mais presentes nas preparações que compõem o dia. Todas as semanas analisadas apresentaram uma média de $74,5 \%(\mathrm{~N}=249)$ de fonte de carboidrato, 15,4\% ( $\mathrm{N}=56)$ de proteínas e 10,1\% $(\mathrm{N}=39)$ de lipídeos (Figura 3).

Figura 3 - Percentual de grupos alimentares mais presentes nos cardápios analisados

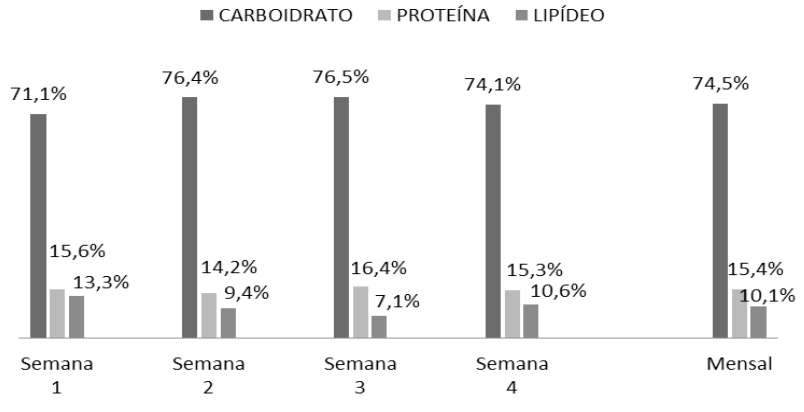

\section{Discussão}

Para Franco (2006), a fome é a carência biológica de alimento que se manifesta em ciclos regulares, o apetite é um estado mental, uma sensação que tem muito mais de psicológico do que fisiológico e o homem é cerimonioso no comer, quer dizer que não come somente para saciar a fome. Para ele, o alimento se reveste também de valor simbólico e a refeição em si é vista como "a ritualização da repartição de alimentos".

Uma alimentação de qualidade promove saúde. Quanto mais variado, diverso e prático o cardápio, mais os clientes optam pela escolha do lugar para realizar, se- em grupos. Dessa forma, nasceu o self-service ou restaurante de "autosserviço", uma modalidade que surgiu para atender à necessidade de uma alimentação mais variada e rápida, em que o serviço é assumido em sua maioria ou quase totalidade pelo cliente, evidentemente com a intenção de reduzir custos e, por conseguinte os preços, aumentando a rapidez no serviço (TEIXEIRA, 2004).

O Guia Alimentar para a População Brasileira (BRASIL, 2014) aponta que esse tipo de serviço está bastante popularizado e que se paga pelo peso da comida selecionada pelo cliente, além de oferecerem grande variedade de alimentos preparados na hora e são melhores alternativas para o dia a dia.

Diante disso, surge a necessidade de se oferecer um cardápio nutricionalmente balanceado, pois os clientes desses restaurantes geralmente fazem essas refeições durante toda a semana. Analisando as técnicas de cocção, do cardápio avaliado, na média das semanas, foi possível verificar que a maioria das preparações é de cocção úmida $(67,9 \%)$, ou seja, não sendo utilizada gordura na preparação.

De acordo com o estudo de Costa (2012), que avaliou duas creches do DF, $50 \%$ das preparações também foram de calor úmido, isso revela uma na utilização de técnicas de cocção em que não se utiliza gorduras e óleos, ou seja, métodos mais saudáveis. Foi analisado também que grande maioria dos dias avaliados apresentou pelo menos uma preparação em calor misto $(6,1 \%)$. Foi verificado que apenas 5,6\% das preparações eram feitas utilizando frituras (calor seco).

Na UAN estudada, a semana 1 apresentou maior ocorrência de frituras $(5,6 \%)$ no cardápio devido à oferta de alimentos industrializados fritos, como a batata palha. A justificativa para o uso foi de que esses alimentos estavam com validade perto do vencimento e deveriam ser consumidos para evitar desperdício, o que, nas outras semanas, já foi notado a redução na oferta desses alimentos no cardápio. Apesar de ter frituras em todas as semanas, a prevalência mensal é relativamente baixa $(5,6 \%)$ e isso mostra que há mais ofertas de preparações mais saudáveis, onde não há o uso de gordura sob imersão para o preparo. No trabalho realizado por Costa (2012), observou-se uma média de 2,2\% de ocorrência de frituras no cardápio das creches avaliadas em Brasília, e Prado (2013) encontrou $11 \%$ de oferta de frituras.

A maior disponibilidade de fornos e chapas pode reduzir a presença de frituras no cardápio tem sido reali- 
zada, pois disponibiliza métodos de preparo sem uso de gordura sob imersão (PRADO, 2013). Esses resultados mostram que o nutricionista responsável pela elaboração do cardápio se preocupa em oferecer preparações mais saudáveis, assim preservando pela saúde de sua clientela.

Apesar da média mensal apresentar maior prevalência de carnes bovinas ou suínas (53,1\%), estas recebem técnicas de cocção com pouca gordura (grelhadas e assadas). E, com a oferta de três tipos de pratos principais, há preocupação do nutricionista em não deixar todas essas preparações com a mesma técnica de cocção em um mesmo dia. Costa (2012) observou a ocorrência de $50 \%$ de carnes gordurosas, porém utilizando métodos de cocção com pouca gordura. É importante destacar que o consumo excessivo pode levar à obesidade, dislipidemias, doenças ateroscleróticas, cardiovasculares e cânceres (SPOSITO et al., 2007). A grande quantidade de gordura saturada e colesterol devem ser substituídos por carnes magras (PRADO, 2013).

A respeito da oferta de frutas e hortaliças no cardápio, estas são servidas todos os dias. As hortaliças estão presentes em grande variedade no bufê de saladas, no balcão de distribuição e as frutas servidas ao final do balcão como opões de sobremesa. As frutas e hortaliças oferecidas se repetem diariamente no cardápio independentemente da safra e do preço. Veiros e Proença (2003) estudaram o cardápio de uma UAN de Florianópolis-SC e observaram a ocorrência de $82,6 \%$ de folhosos no cardápio, enquanto Passos (2008) estudou uma UAN em Brasília-DF e observou 94,2\%. E, Costa (2012), observou a presença de $100 \%$ de folhosos no cardápio das creches estudadas. A presença de frutas e hortaliças na dieta garante o balanceamento do prato, além de serem ricas em vitaminas e minerais e promoverem o aporte de fibras na dieta.

Para Ornellas (2001), um bom cardápio deve apresentar dois princípios básicos: variedade e harmonia. A variedade consiste na variação da oferta de alimentos, dos sabores predominantes, da consistência, da temperatura e das cores. A harmonia é favorecida pela associação exata das cores, de consistência e sabores, o que exige o sentido estético e artístico. E, sabendo disso, é possível verificar que a nutricionista do local estudado trabalha com essa técnica, a fim de que as preparações não sejam monótonas visualmente, pois $100 \%$ do cardápio apresentava combinação de cores tornando as preparações coloridas.

Veiros e Proença (2003) observaram que 65,1\% de preparações analisadas tinham semelhanças de cores, já Passos (2008) notou em 58,6\% e Costa (2012) observou que as duas creches estudadas apresentavam problemas com monotonia de cores devido à baixa disponibilidade da oferta de frutas e hortaliças.

É de preocupação do nutricionista na montagem dos cardápios verificar se as cores tanto de salada, pratos principais e guarnições não se repetem, buscando sempre deixar bem coloridas as preparações com o foco maior nas cores do bufê de salada, a fim de chamar mais atenção do cliente para o prato saudável. A monotonia de cores interfere na qualidade e ofertas de nutrientes, entre estes as fibras, vitaminas e minerais. A textura também é bem cuidada, como dito anteriormente, a respeito das técnicas de cocção. Os cardápios quando elaborados por nutricionista, tendem a ser mais coloridos e nutricionalmente adequados (PRADO, 2013).

Em relação aos grupos alimentares mais presentes, pode-se observar que o mais oferecido no cardápio são os carboidratos $(74,5 \%)$, o que se encontra dentro do resultado esperado devido à oferta diária do arroz, macarrão e vegetais cozidos. Com relação às proteínas, houve percentual de $15,4 \%$, o que pode ser explicado pela oferta diária de três opções de carnes no cardápio e, a respeito dos lipídeos $(10,1 \%)$, esse valor se dá por conta da farofa que é servida diariamente. No estudo de Costa (2012), a maior prevalência também foi de carboidratos $(70,4 \%)$, a proteína avaliada em uma das creches teve percentual alto de $31,4 \%$ devido à presença constante de leite no cardápio.

Segundo as recomendações diárias nutricionais (DRIS), 55 a 75\% devem ser proveniente de carboidrato (45 a 65\% devem ser provenientes de carboidratos complexos e fibras e menos de $10 \%$ de açúcares livres), 10 a $15 \%$ proteína e 15 a $30 \%$ de lipídeos. O que indica que todos os cardápios avaliados, em relação à oferta de macronutrientes, estão adequados para a população adulta considerando uma dieta de 2000 quilocalorias (Kcal) (BRASIL, 2014).

\section{Conclusão}

A rotina de comer fora de casa é um fator que pode estar associado diretamente à obesidade. Quando a pessoa pratica esse ato com frequência, geralmente não consegue controlar a quantidade de alimentos que está consumindo diariamente, além de não saber o modo de 
preparo dos alimentos e os ingredientes que os compõem.

Os restaurantes do tipo self-service, apesar da grande variedade de preparações, são vilões para a obesidade, pois ofertam grande variedade de preparações, além de terem, muitas vezes, opções como churrasco, massas feitas na hora, salgadinhos fritos, dentre outros alimentos não saudáveis.

Entretanto a UAN estudada tem a preocupação com as preparações servidas, como visto, as carnes gordurosas recebem técnicas de cocção que utilizam métodos de preparo sem gordura, são mais saudáveis e com texturas diversificadas e variadas. Das técnicas de cocção utilizadas, a com maior prevalência foi de calor úmido $(67,9 \%)$ o que indica que a maioria das preparações são cozidas sendo referências para preparações mais saudáveis. E a oferta de frutas e hortaliças está adequada para favorecer a saúde e dar cor aos pratos, pois estão presentes diariamente.

O nutricionista tem o papel de promover programas de educação alimentar e nutricional para os clientes, além de planejar, elaborar e avaliar os cardápios, adequando ao perfil epidemiológico da clientela atendida, servindo no local as preparações que estejam associadas aos hábitos alimentares dos clientes, e incentivando o consumo de alimentos saudáveis.

\section{Referências}

BRASIL. Ministério da Previdência Social. Portaria Interministerial $n^{\circ}$ 66, de 25 de agosto de 2006. Altera os parâmetros nutricionais do Programa de Alimentação do Trabalhador - PAT. Disponível em: <http://crn3.org.br/legislacao/ doc/portaria66_25_08_06.pdf $>$. Acesso em: 21 out. 2015.

BRASIL. Ministério da Saúde. Guia alimentar para a população brasileira: promovendo a alimentação saudável. Brasília: MS, 2014.

CLARO, R. M. et al. Influência da renda sobre as despesas com alimentação fora do domicílio, no Brasil, 20022003. Cadernos de Saúde Pública, Rio de Janeiro, v. 25, n. 11, p. 2989-2496, nov. 2009. doi: 10.1590/S0102311X2009001100018.

COSTA, S. E. P.; MENDONÇA, K. A. N. Avaliação qualitativa de cardápios oferecidos para pré-escolares de creches do Distrito Federal. Universitas: Ciências da Saúde, Brasília, v. 10, n. 1, p. 33-40, jan./jun. 2012. doi: 10.5102/ ucs.v10i1.1588
FRANCO, A. De caçador a gourmet: uma história da gastronomia. São Paulo: Senac, 2006.

INSTITUTO BRASILEIRO DE GEOGRAFIA E ESTATÍSTICA. Pesquisa de Orçamentos Familiares 2008-2009: despesas, rendimentos e condições de vida. Rio de Janeiro: IBGE, 2010.

LEAL, D. Crescimento da alimentação fora do domicílio. Segurança Alimentar e Nutricional, Campinas, v. 17, n. 1, p. 123-132, jan./jun. 2010.

LIMA, D. M. et al. Tabela brasileira de composição de alimentos. 2. ed. Campinas: Fórmula, 2006.

MAHAN, L. K.; ESCOTT-STUMP, S. Krause: alimentos, nutrição e dietoterapia. 11. ed. São Paulo: Roca, 2003.

ORNELLAS, L. H. Técnica dietética: seleção e preparação de alimentos. 7. ed. São Paulo: Atheneu, 2007.

ORNELLAS, L. H. Técnica dietética: seleção e preparo de alimentos. 7. ed. São Paulo: Atheneu, 2001.

PASSOS, A. L. A. Análise do cardápio de uma unidade de alimentação e nutrição institucional em Brasília-DF segundo o método “avaliação qualitativa das preparações do cardápio. 2008. 28 f. Monografia (Pós-graduação) Curso de Especialização em Gastronomia e Saúde, Centro de Excelência em Turismo, Universidade de Brasília, 2008.

PRADO, B. G, et al. Avaliação qualitativa das preparações de cardápio em uma Unidade de Alimentação e Nutrição de Cuiabá - MT. UNOPAR Científica Ciências Biológicas Saúde, Londrina, v. 15, n. 3, p. 219-223, jul./set. 2013.

SPOSITO, A. et al. IV Diretriz Brasileira sobre Dislipidemias e Prevenção da Aterosclerose: departamento de aterosclerose da Sociedade Brasileira de Cardiologia. Arquivos Brasileiros de Cardiologia, Rio de Janeiro, v. 88 , p. 2-19, abr. 2007. Suplemento 1. doi: 10.1590/S0066$782 \times 2007000700002$.

TEXEIRA, S. et al. Administração aplicada às Unidades de Alimentação e Nutrição. São Paulo: Atheneu, 2004.

VEIROS, M. B.; PROENÇA, R. P. C. Avaliação qualitativa das preparações do cardápio em uma unidade de alimentação e nutrição: método AQPC. Nutrição em Pauta, São Paulo, ano 11, n. 62, set./out. 2003. 